\title{
Influence of Agitation Rate on the Growth of MD2 Pineapple Protocorm-Like Bodies and Shoots in Liquid-Shake Culture
}

\author{
Zuraida Ab Rahman ${ }^{*}$, Hartinee Abbas ${ }^{2}$, Ayu Nazreena Othman', Wan Zaliha Wan Sembok ${ }^{3}$ \\ ${ }^{1}$ Biotechnology and Nanotechnology Research Centre, Malaysian Agricultural Research and Development Institute (MARDI), \\ Kuala Lumpur, Malaysia \\ ${ }^{2}$ Horticulture Research Centre, Malaysian Agricultural Research and Development Institute (MARDI), Sintok, Malaysia \\ ${ }^{3}$ School of Food Science and Technology, Universiti Malaysia Terengganu, Kuala Terengganu, Malaysia \\ Email: *azuraida@mardi.gov.my
}

How to cite this paper: Rahman, Z.A., Abbas, H., Othman, A.N. and Sembok, W.Z.W. (2019) Influence of Agitation Rate on the Growth of MD2 Pineapple Protocorm-Like Bodies and Shoots in Liquid-Shake Culture. American Journal of Plant Sciences, 10, 1233-1238.

https://doi.org/10.4236/ajps.2019.107088

Received: June 12, 2019

Accepted: July 28, 2019

Published: July 31, 2019

Copyright $\odot 2019$ by author(s) and Scientific Research Publishing Inc. This work is licensed under the Creative Commons Attribution International License (CC BY 4.0).

http://creativecommons.org/licenses/by/4.0/

\begin{abstract}
The present study was conducted to investigate the effect of agitation rate on the increase in fresh weight of MD2 pineapple protocorm-like bodies (PLBs) and shoots cultured in liquid medium. PLBs were cultured in $250 \mathrm{ml}$ Erlenmeyer flasks (7 g per flask) containing MS medium and plant growth regulators $(1.5 \mathrm{mg} / \mathrm{L}$ 6-Benzylaminopurine, BAP and $0.2 \mathrm{mg} / \mathrm{L}$ 1-Naphthaleneacetic acid, NAA). The orbital shaker was set at speeds of 50, 80, 100, 120, and 150 rpm. After 40 days, the cultures shaken at $80 \mathrm{rpm}$ showed the highest fresh weight and the highest number of shoots at $76 \mathrm{~g}$ and 41 shoots, respectively. A comparative study of agitation found that $80 \mathrm{rpm}$ was the best speed which enhanced both PLB and shoot formation. The findings in the present study would be helpful in setting up large-scale in vitro mass propagation of MD2 pineapple.
\end{abstract}

\section{Keywords}

Pineapple MD2, Micropropagation, Liquid-Shake Culture, Agitation Rate

\section{Introduction}

A lack of plant material is a major problem faced by the Malaysian pineapple industry. This is due to the continued growth of pineapple cultivation areas and the increasing demand for MD2 plant materials. In conventional pineapples breeding, the selection method is tedious and needs several generations of backcrossing to develop a stable cultivar with desired traits [1]. The pineapple (Ana- 
nas comosus), a tropical species, is the most economically significant plant in the family Bromeliaceae [2] [3]. The plants begin flowering after five to ten months and set fruit in the following six months [4]. The pineapple is a major tropical fruit in terms of world production [5], with the MD2 variety being among the highly commercialized cultivars especially popular in the European Union market [6]. The National Key Economic Area (NKEA) under Malaysia's Permanent Food Production Area has listed MD2 as one of the top seven tropical fruits in terms of production output in Malaysia [7].

The variety, a deep golden fruit, is in high demand owing to its aroma, blemish-free flesh and high sugar content, besides being rich in vitamins $\mathrm{A}, \mathrm{B}$, and C, ripening evenly and having a long shelf life [8] [9]. Pineapples can be cultivated from cuttings obtained from the top of the fruit. Micropropagation of MD2 pineapple has also been reported through direct in vitro micropropagation [8] and indirect regeneration [1]. Multiple plantlets can be produced in vitro using liquid-shake culture, this approach attaining an increase of up to four-fold as compared with culture on solid medium [10]. The aim of the study was to investigate the effect of agitation rate of the orbital shaker on MD2 pineapple propagation and quality, and to compare these results with those obtained with cultures on solid medium.

\section{Materials and Methods}

MD2 Pineapple suckers were used in this study. The pieces of MD2 pineapple suckers approximately $25-30 \mathrm{~cm}$ were used as explants for in vitro culture. The pineapple leaf blade removed, the inside of the explant was trimmed to $5-8 \mathrm{~cm}$. It was followed by washed thoroughly in running tap water and detergent. The explant then immersed in fungicide (5\% w/v Benlate) for one hour and rinsing with sterile distilled water. The explants were immersed in CloroxTM (5.25\% sodium hypochlorite) at $50 \%(\mathrm{v} / \mathrm{v})$ for 15 minutes then followed by soaking in 20\% (v/v) CloroxTM for 10 mins. The explant was then rinsed thrice with sterilized distilled water, which all the procedure conducted in a laminar flow chamber. The sterilized explants were then cut to $1-2 \mathrm{~cm}$ pieces as described by $\mathrm{Zu}$ raida et al. (2018) [10].

Sterilized explants were cultured on solid Murashige and Skoog (MS) medium (Murashige and Skoog [11]) that was supplemented with $30 \mathrm{mg} / \mathrm{L}$ sucrose, 5 $\mathrm{mg} / \mathrm{L}$ benzyl aminopurine (BAP) and $0.3 \%$ agar. The cultures were maintained in the medium for three months before sub-culturing on to fresh medium at monthly intervals. After a further three months, the microshoots obtained were maintained in the Murashige and Skoog (MS) liquid medium that was supplemented with $30 \mathrm{mg} / \mathrm{L}$ sucrose, $1 \mathrm{mg} / \mathrm{L}$ benzyl aminopurine (BAP) and $0.1 \mathrm{mg} / \mathrm{L}$ 2,4-Dichlorophenoxyacetic acid (2,4-D) for three months before sub-culturing into fresh medium at monthly intervals. After a further three months, the protocorm-like bodies (PLBs) (Figure 1(a)) obtained were transferred on to liquid medium in $250 \mathrm{ml}$ shaking flasks, oscillating at $120 \mathrm{rpm}$ to obtain the plant material 

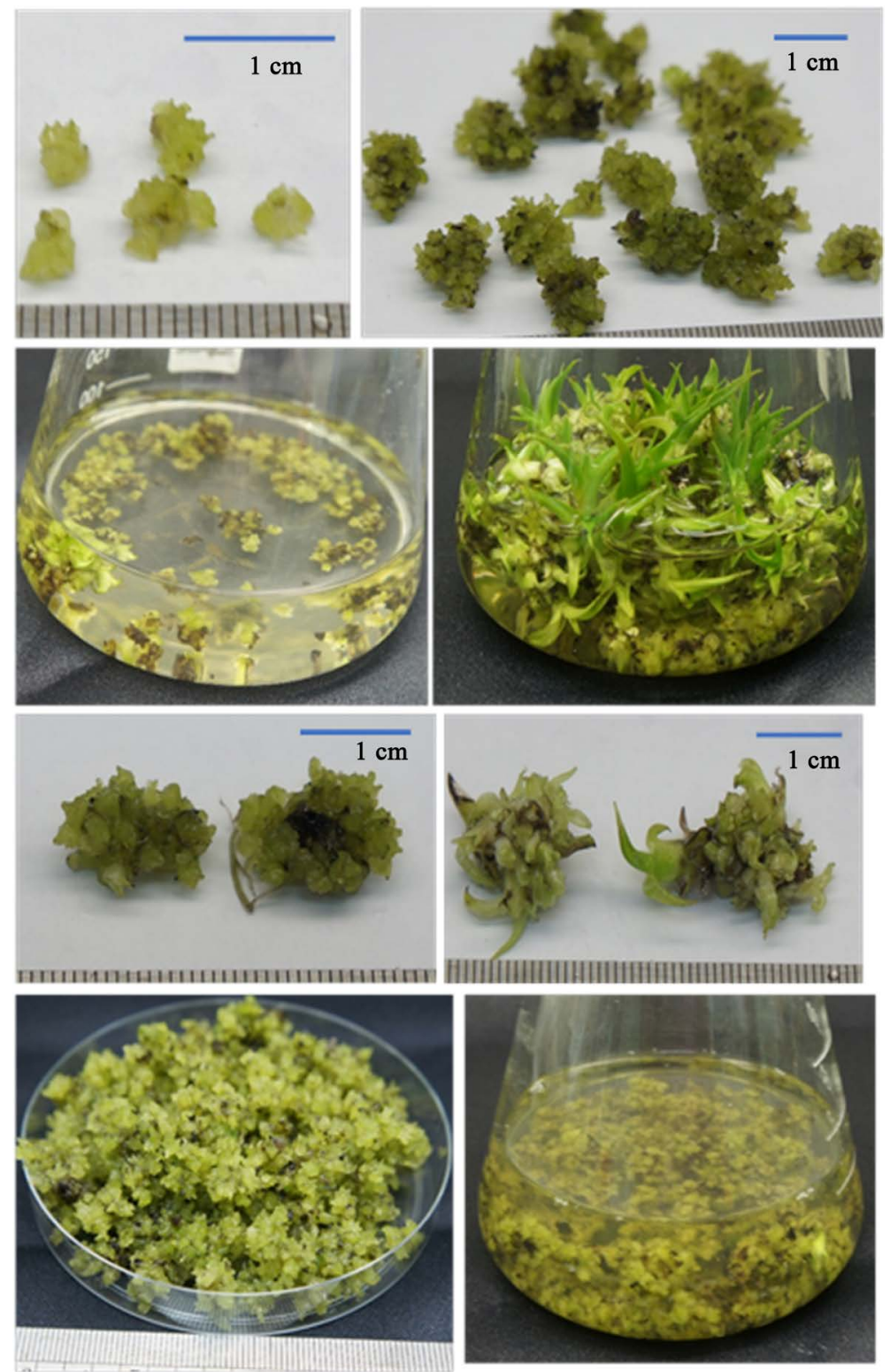

Figure 1. Development of pineapple protocorm-like bodies. (a) Protocorm-like bodies (PLBs); (b) PLBs with initial shoots; (c) PLBs cultured in a $250 \mathrm{ml}$ flask containing MS liquid medium supplemented with $1.5 \mathrm{mg} / \mathrm{L} \mathrm{BAP}$ and $0.2 \mathrm{mg} / \mathrm{L}$, at the beginning of the experiment; (d) Culture in liquid medium shaken at $80 \mathrm{rpm}$ showing green coloration and expanded, well-developed leaves; ((e), (f)) Culture in liquid medium shaken at 80 rpm; (g) Culture in liquid medium shaken at $120 \mathrm{rpm}$ showing increased fresh green PLB production; (h) Culture in liquid medium shaken at $150 \mathrm{rpm}$, showing good growth despite brownish appearance due to the presence of phenolics.

used in the study. After a month, most of the treatment showed increasing in.

In each treatment, $7 \mathrm{~g}$ pineapple PLBs were cultured in $250 \mathrm{ml}$ flasks containing MS liquid medium supplemented with $1.5 \mathrm{mg} / \mathrm{L} \mathrm{BAP}$ and $0.2 \mathrm{mg} / \mathrm{L}$ NAA (Figure $1(\mathrm{c})$ ). The $\mathrm{pH}$ of the medium was adjusted to 5.8 , then autoclaving at $121^{\circ} \mathrm{C}$ for 15 mins. The cultures of PLBs were placed on orbital shakers set at different rates of agitation, i.e. 50, 80, 100, 120, and $150 \mathrm{rpm}$. Solid medium (SL) 
cultures and static liquid cultures with no shaking (SLC) were used as controls. All cultures were maintained in the growth room at $25^{\circ} \mathrm{C}$ under cool-white fluorescent lighting (12 hours light/darkness). Measurements were expressed as total fresh weight (PLBs and plantlets) and the number of shoots produced after 40 days in culture. Total fresh weight was recorded after the samples were dried on filter paper for 1 hour to remove surface water. A completely randomized design was adopted, with 10 flasks used for each treatment. The means and standard deviations (indicated as \pm values) were calculated for the treatment responses. Statistical analyses were performed using SPSS software.

\section{Results and Discussion}

After forty days of cultivation in liquid medium containing $1.5 \mathrm{mg} / \mathrm{L} \mathrm{BAP}$ and $0.2 \mathrm{mg} / \mathrm{L}$ NAA, the PLBs in all shaking treatments showed increases in growth. The highest total fresh weight of $76 \mathrm{~g}$ was obtained with shaking at $80 \mathrm{rpm}$. One third of the cultures in this treatment produced shoots that were characterized by intense green coloration and well-developed expanded leaves (Figure 1(c), Figure 1(d)). The PLBs obtained with this treatment were bigger than those in the other treatments, showed clumping and produced more shoots (Figure 1(e), Figure 1(f)). Cultures that were shaken at a lower rate $(50 \mathrm{rpm})$ or higher rate $(100 \mathrm{rpm})$ produced $63 \mathrm{~g}$ and $61 \mathrm{~g}$ of tissue fresh weight (Figure 2). Both the 50 rpm and $100 \mathrm{rpm}$ treatments also produced shoots, whereas few shoots were produced when the PLBs were cultured in flasks shaking at $120 \mathrm{rpm}$, and none at $150 \mathrm{rpm}$. The highest number of offshoots (41 per flask) was obtained in cultures shaken at $80 \mathrm{rpm}$ (Figure 3). Shaking at $120 \mathrm{rpm}$ resulted in the production of more PLBs that appeared fresh and green (Figure 1(g)). PLBs in flasks shaken at $150 \mathrm{rpm}$ turned brown due to the presence of phenolics, but were still growing well nonetheless (Figure $1(\mathrm{~h})$ ). The control cultures on solid medium and on

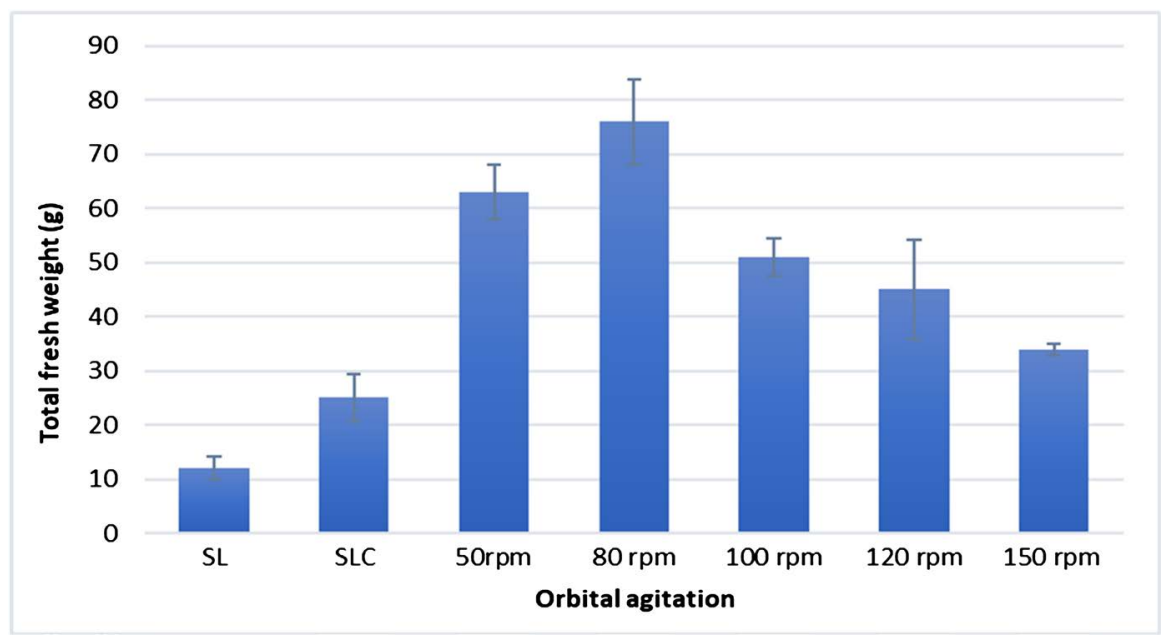

Figure 2. Effect of different agitation rates on total fresh weight (PLBs and plantlets) of pineapple cultured in vitro in MS medium containing $1.5 \mathrm{mg} / \mathrm{L} \mathrm{BAP}$ and $0.2 \mathrm{mg} / \mathrm{L} \mathrm{NAA}$ after 40 days. The error bars \pm in the figure indicate the standard deviations from 10 samples. 


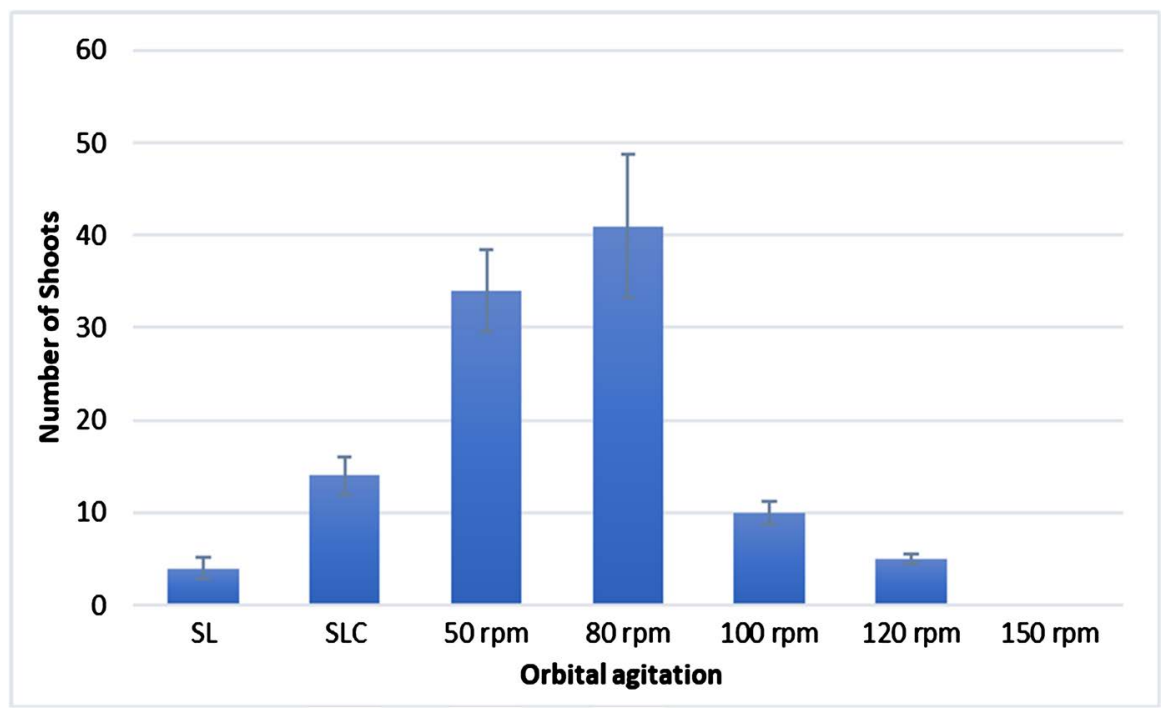

Figure 3. Effect of different agitation rates on the number of shoots of in vitro pineapple cultured in MS medium containing $1.5 \mathrm{mg} / \mathrm{L} \mathrm{BAP}$ and $0.2 \mathrm{mg} / \mathrm{L}$ NAA after 40 days. The error bars \pm in the figure indicate the standard deviations from 10 samples.

unshaken liquid medium showed growth rates lower than those of the shaken cultures (Figure 2). These controls produced some shoots, but fewer in number than from cultures shaken at 50 or $80 \mathrm{rpm}$ (Figure 3).

Liquid culture systems tend to enhance growth and propagation as compared with solid medium cultures. According to Zuraida et al. [10], liquid-shake cultures are better at producing multiple shoots as compared with solid medium cultures. The continuous shaking or a rotary shaker probably facilitates increased uptake of the nutrients in the medium [12] [13]. Hamid et al. [1] reported that the highest number of pineapple shoots obtained on solid MS medium containing $3 \mathrm{mg} / \mathrm{L} \mathrm{BAP}+1 \mathrm{mg} / \mathrm{L}$ NAA was only 15 . Hence, the liquid medium with shaking at $80 \mathrm{rpm}$ used in the present study performed far better in shoot multiplication. In vitro growth, multiplication and elongation of Celastrus bolivitianum have also been observed to be improved in liquid culture as compared with solid medium [14]. The improved growth in liquid system may be attributed to the absence of interfering impurities from agar and the better availability of water and nutrients [15].

\section{Conclusion}

Liquid-shake culture systems are conducive to the development of MD2 pineapple PLBs and shoots. Such a system is suitable for the tissue culture of MD2 pineapple for rapid and efficient clonal propagation. This finding suggested to great potential for upscaling the production of MD2 pineapple using liquid culture in the bioreactor system.

\section{Acknowledgements}

The authors would like to thank the Malaysian Agricultural Research and De- 
velopment Institute (MARDI) for providing financial support under the RMK11 Research Grant.

\section{Conflicts of Interest}

The authors declare no conflicts of interest regarding the publication of this paper.

\section{References}

[1] Hamid, N.S., Bukhori, M.F.M. and Jalil, M. (2013) Direct and Indirect Plant Regenerations of Pineapple var. MD2 (Ananas comosus L.). Malaysian Applied Biology Journal, 42, 61-66.

[2] Morton, J.F. (1987) Pineapple, Ananas comosus.

[3] Coppens d'Eeckenbrugge, G. and Leal, F. (2003) Morphology, Anatomy, and Taxonomy. In: Bartholomew, D.P., Paull, R.E. and Rohrbach, K.G., Eds., The Pineapple: Botany, Production, and Uses, CABI Publishing, Wallingford, 21.

[4] Birgit, B. (2010) Pineapple Growing. http://tropicalpermaculture.com

[5] FAOSTAT (2010) Tropical Fruits. http://www.fao.org/3/y5143e/y5143e1a.htm

[6] Anonymous (2006) Pineapple News. Newsletter of the Pineapple Working Group, International Society for Horticultural Science.

[7] Malaysian Pineapple Industry Board. http://www.mpib.gov.my

[8] Danso, K.E., Ayeh, K.O., Oduro, V., Amiteye, S. and Amoatey, H.M. (2008) Effect of 6-Benzylaminopurine and Naphthalene Acetic Acid on in Vitro Production of MD2 Pineapple Planting Materials. World Applied Sciences Journal, 3, 614-619.

[9] Akbar, M.A., Karmarka, B. and Roy, S. (2003) Callus Induction and High Frequency Plant Regeneration of Pineapple (Ananas comosus L. Merr.). Plant Tissue Culture, 13, 109-116.

[10] Rahman, Z.A., Abbas, H. and Othman, A.N. (2018) Rapid Micropropagation of MD2 Pineapple (Ananas comosus L.) Using the Temporary Immersion Systems (TIS) and Liquid-Shake Culture (LSC). Asian Journal of Science and Technology, 9, 8833-8836.

[11] Murashige, T. and Skoog, F. (1962) A Revised Medium for Rapid Growth and Bioassays with Tobacco Tissue Cultures. Physiologia Plantarum, 15, 473-497. https://doi.org/10.1111/j.1399-3054.1962.tb08052.x

[12] Akin-Idowu, P.E., Solomon Akinyemi, S.O. and Olubunmi Ibitoye, D. (2014) Influence of Medium Type and Growth Regulators on in Vitro Micropropagation of Pineapple (Ananas comosus (L.), var. Smooth cayenne). African Journal of Plant Science, 8, 450-456. https://doi.org/10.5897/AJPS2014.1184

[13] Ziv, M (2005) Simple Bioreactors for Mass Propagation of Plants. In: Hvoslef-Eide, A.K. and Preil, W., Eds., Liquid Culture Systems for in Vitro Plant Propagation, Springer-Verlag, Dordrecht, 79-94. https://doi.org/10.1007/1-4020-3200-5_5

[14] Vyas, S., Rao, M.S., Suthar, R.K. and Purohit, S.D. (2008) Liquid Culture System Stimulates in Vitro Growth and Shoot Multiplication in Four Medicinally Important Plants. Medicinal and Aromatic Plant Science and Biotechnology, 2, 96-100.

[15] Etienne, H. and Berthouly, M. (2002) Temporary Immersion Systems in Plant Micropropagation. Plant Cell, Tissue and Organ Culture, 69, 215-231. https://doi.org/10.1023/A:1015668610465 